\title{
Physicochemical Effects of Humid Air Treated with Infrared Radiation on Aqueous Solutions
}

\author{
Olga Yablonskaya ${ }^{1, *}$, Vladimir Voeikov ${ }^{2}$, Ekaterina Buravleva ${ }^{2}$, Aleksei Trofimov ${ }^{1}$ and Kirill Novikov ${ }^{2}$ \\ 1 N.M. Emanuel Institute of Biochemical Physics, RAS, 119334 Moscow, Russia; avt_2003@mail.ru \\ 2 Faculty of Biology, M.V. Lomonosov Moscow State University, 119234 Moscow, Russia; \\ v109028v1@yandex.ru (V.V.); b_u_k_a@mail.ru (E.B.); kirniknov@yandex.ru (K.N.) \\ * Correspondence: olga.yablonsky@gmail.com
}

Citation: Yablonskaya, O.; Voeikov,

V.; Buravleva, E.; Trofimov, A.;

Novikov, K. Physicochemical Effects

of Humid Air Treated with Infrared

Radiation on Aqueous Solutions.

Water 2021, 13, 1370. https://

doi.org/10.3390/w13101370

Academic Editors:

Maksim Pakhomov and

Pavel Lobanov

Received: 26 March 2021

Accepted: 11 May 2021

Published: 14 May 2021

Publisher's Note: MDPI stays neutral with regard to jurisdictional claims in published maps and institutional affiliations.

Copyright: (C) 2021 by the authors. Licensee MDPI, Basel, Switzerland. This article is an open access article distributed under the terms and conditions of the Creative Commons Attribution (CC BY) license (https:/ / creativecommons.org/licenses/by/ $4.0 /)$.

\begin{abstract}
Water vapor absorbs well in the infrared (IR) region of the spectra. On the other hand, it was recently demonstrated that IR radiation promotes formation of the so-called exclusion zones (EZ) at the interfaces between hydrophilic surfaces and water. EZ-water properties differ significantly from that of bulk water. It was studied for the first time whether treatment of water with humid air irradiated with IR-C band could change its physical-chemical properties, making it EZ-water-like. Humid air irradiated with IR was called coherent humidity $(\mathrm{CoHu})$. Redox potential and surface tension decreased in deionized water and mineral water samples that were treated with CoHu, while dielectric constant increased in such water samples. After such treatment of carbonate or phosphate buffers, their buffer capacity against acidification and leaching significantly increased. No such changes were observed in water samples treated with non-irradiated humid air. Thus, after treatment of tested aqueous systems with humid air exposed to IR radiation, their properties change, making them more like EZ-water. The results suggest that IR irradiation of humid air converts it into a carrier of a certain physical signal that affects water properties.
\end{abstract}

Keywords: water vapor; coherent phase; exclusion zone; redox potential; $\mathrm{pH}$; infrared; microdroplets

\section{Introduction}

There is more and more evidence that water, the most common substance in nature and in particular in all living organisms, performs not only the function of a solvent, but also carries certain active functions due to its ability to cooperate and form supramolecular structures with physicochemical properties that differ from those expected for the ideal homogeneous water [1,2]. Indeed, atomic force microscopy allowed to image up to millimeter large stable water clusters consisting of millions of water molecules present in bulk water [3]. An idea of heterogeneous water was also supported by the dynamic light scattering that allowed to detect stable supramolecular complexes in the range of hundreds of nanometers in water that could be formed and reorganized, which at least complements the flickering water clusters model that was suggested earlier [4]. Mae Wan Ho et al. demonstrated that water inside living organisms, unlike bulk water, exhibits properties of a liquid crystal [5]. X-ray emission spectroscopy and neutron diffraction study provided evidence that there is high-density water and low-density water [6,7]. According to these authors, high-density water is characterized by strong hydrogen bonds between molecules surrounded by low-density water with weak hydrogen bonds.

Formation of heterogeneous water is often triggered by particles in water and by surfaces that it wets. The phenomenon of the formation of negatively charged exclusion zones (EZ) in water at hydrophilic surfaces that exclude most solute molecules and have peculiar physicochemical properties has been described years ago [8]. The size of EZ-water varies from tens of nanometers to hundreds of microns, depending on the properties of the surface, quality of water and electromagnetic influences on water [9]. Thus, illumination with infrared (IR) light leads to the increase of EZ as it weakens bonding between water 
molecules in bulk water adjacent to EZ-water, and "free" water dipoles are attracted to the negatively charged EZ-water region and support its buildup [10]. In another study, the formation of structured water with the use of infrared radiation emitting ceramic powder without its contact with water was demonstrated [11]. As all liquids of a living organism are constantly in contact with hydrophilic surfaces (biopolymeric molecules, supramolecular complexes, cell surfaces), EZ research is important for understanding the fundamental mechanisms of biological action.

Absorption characteristics of IR light by water are determined by rotation and vibration of its molecules. According to Hamashima et al., the spectral signature of a fully hydrated, four-coordinated water molecule is in the hydrogen-bonded $\mathrm{O}-\mathrm{H}$ stretch region of the IR spectra at 3000-3600 $\mathrm{cm}^{-1}$, depending on the cluster size [12]. In liquid water, hydrogen bonding limits rotational and vibrational changes of water molecules that occur after adsorption of visible and infrared light. In vapor, the gaseous state, rotation of the water molecule is free, combined with stretching and bending of the $\mathrm{O}-\mathrm{H}$ bonds of water with absorption in the IR spectra region, and leads to a huge number of rotational and vibrational combinations $[13,14]$. Interestingly, large, hydrogen-bonded water clusters of water molecules make the major contribution to water vapor and humid air absorption in IR regions where individual water molecules do not absorb [15]. The ratio of water liquid-to-vapor IR absorption coefficients can be as high as $10^{4}$. Researchers suggested a hypothesis that water vapor anomalous adsorption can be explained by the presence of areas in vapor rich with hydrogen bonding, which resembles liquid water, whose hydrogen bonds adsorb intensely in the IR region. It is the presence of hydrogen bonds that is responsible for the absorption of electromagnetic energy by clusters in the infrared range. This peculiar adsorption was regarded as an indicator of the presence of water clusters. However, these clusters were considered neutral and uncharged.

There is experimental proof that aqueous systems are capable of storage, modification and transmission of external electro-magnetic signals from a source molecule to biological targets, specifically affecting their endogenous activity and closely resembling the effect of a source molecule via a resonance effect [16]. Here, we irradiate humid air with IR energy with the wavelength of $4000 \mathrm{~nm}$ and inquire if such air can change the properties of distilled and mineral bottled waters.

\section{Materials and Methods}

\subsection{Water Preparation}

Type I pure deionized water was prepared with Millipore Direct Q3, Merck, and stored in a $500 \mathrm{~mL}$ sterile dark borosilicate glass bottle. Senezhskaya and BioVita mineral waters were purchased in $1.5 \mathrm{~L}$ plastic bottles. The chemical characteristics of Senezhskaya water were as follows: $\mathrm{pH} 7.52,\left[\mathrm{HCO}_{3}{ }^{-}\right] 350 \mathrm{mg} / \mathrm{L},\left[\mathrm{Na}^{+}\right] 5.5 \mathrm{mg} / \mathrm{L},\left[\mathrm{K}^{+}\right] 11.8 \mathrm{mg} / \mathrm{L},\left[\mathrm{Ca}^{2+}\right]$ $67 \mathrm{mg} / \mathrm{L},\left[\mathrm{Na}^{+}\right] 6.9 \mathrm{mg} / \mathrm{L},\left[\mathrm{Mg}^{2+}\right] 27 \mathrm{mg} / \mathrm{L},\left[\mathrm{Cl}^{-}\right] 39 \mathrm{mg} / \mathrm{L}$, total hardness 5.2 grains/gal, total mineralization $496 \mathrm{mg} / \mathrm{L}$. The chemical characteristics of BioVita water were as follows: $\mathrm{pH}$ 7.6, $\left[\mathrm{HCO}_{3}{ }^{-}\right] 487 \mathrm{mg} / \mathrm{L},\left[\mathrm{Na}^{+}\right] 7.4 \mathrm{mg} / \mathrm{L},\left[\mathrm{K}^{+}\right] 17.3 \mathrm{mg} / \mathrm{L},\left[\mathrm{Ca}^{2+}\right] 94 \mathrm{mg} / \mathrm{L},\left[\mathrm{Na}^{+}\right]$ $6.9 \mathrm{mg} / \mathrm{L},\left[\mathrm{Mg}^{2+}\right] 20 \mathrm{mg} / \mathrm{L},\left[\mathrm{Cl}^{-}\right] 49 \mathrm{mg} / \mathrm{L}$, total hardness 5.5 grains/gal, total mineralization $513 \mathrm{mg} / \mathrm{L}$, and measurements were performed according to standard specifications presented by the American public health association [17]. Water from bottles was transferred in $500 \mathrm{~mL}$ sterile dark borosilicate glass bottles. Then, the bottles were left in a dark place at room temperature and were treated with humid air irradiated with IR afterwards.

\subsection{Water Treatment}

CoHu was produced with a NanoVi Exo (Eng 3 Corporation, Seattle, WA, USA) device that generates humid air with particles 1-10 $\mu \mathrm{m}$ in size out of pure distilled water (Figure 1). The device consists of a humidifier, excitation unit and a control unit. The method involves humidification of the carrier air with water microdroplets, irradiating it with infrared electromagnetic energy and treatment of bulk water or other objects with the irradiated humid air. Unpurified ambient air with initial humidity of $25-30 \%$ is used as the carrier 
gas. The pump (in) takes in ambient air and presses it through the diffuser to water in the humidifier glass container. The pump (out) takes the humidified air above water in the humidifier glass container and presses it through the quartz glass tube of the excitation unit. Each pump creates an air output of 3-4 L per minute. The pump membrane is made of medical grade silicon rubber. The humidified airstream (70-85\% humidity) goes to the excitation unit equipped with 24 LEDs, a heat sink element and a thermo sensor. The humid air goes through a $40 \mathrm{~mm}$ long quartz glass tube with an inner diameter of $3 \mathrm{~mm}$. Within the glass tube, the water vapor absorbs energy that is emitted by the LEDs placed around the tube at a distance of $2.3 \mathrm{~mm}$. The diameter of each LED is $4.7 \mathrm{~mm}$, and they emit IR energy at about $4000 \mathrm{~nm}$ with a beam cone of $30^{\circ}$ and the output power of $700 \mathrm{pW}$. The control unit allows to switch the LEDs off and to obtain the non-irradiated humid air for control measurements. After exiting the excitation unit, humid air exits the device through the $70 \mathrm{~cm}$ long flexible plastic outlet with the inner diameter of $3.2 \mathrm{~mm}$.

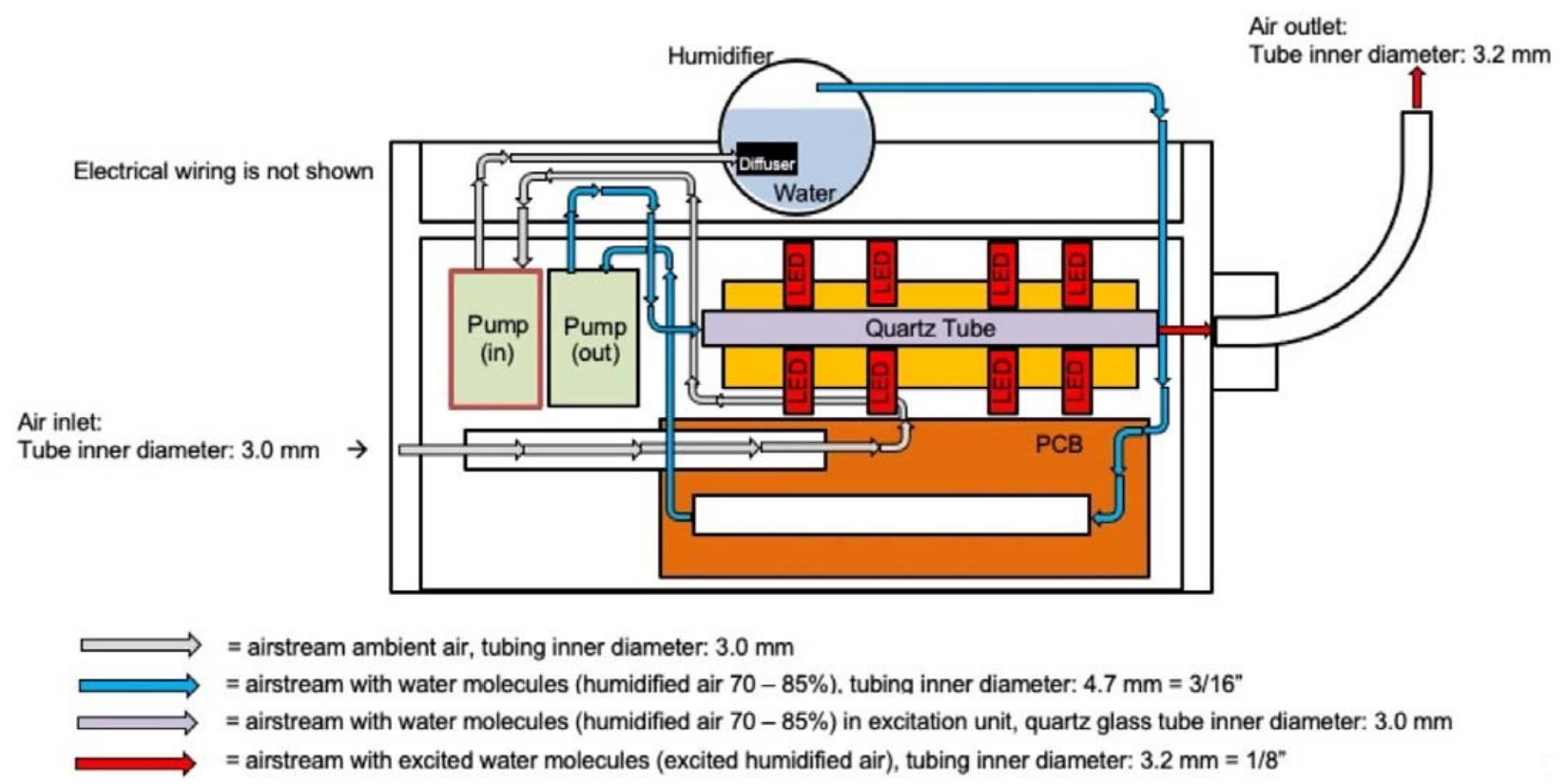

Figure 1. The scheme of the apparatus for $\mathrm{CoHu}$ preparation.

Pure and mineral waters were placed in sterile $20 \mathrm{~mL}$ glass flasks, and a humid air supply tube was placed $5 \mathrm{~cm}$ above the water surface in ambient light. Three parallel $20 \mathrm{~mL}$ samples were treated with $\mathrm{CoHu}$ and non-CoHu for 1 to 3 min depending on experiment design. Two ways of application of $\mathrm{CoHu}$ and non-CoHu were suggested - "blowing" the airstream above the water surface and "bubbling" the airstream via immersion of sterile shortened medical PVC cannula (Philips, Amsterdam, Netherlands) into water samples. Untreated samples were left as controls. Then, the samples were covered with Parafilm, and water parameters were measured within $5 \mathrm{~min}$.

\subsection{Redox Potential Measurement}

Redox potentials were measured using the potentiometer Ekspert-001 (EkoniksEkspert, Moscow, Russia) equipped with combined $\mathrm{Pt} / \mathrm{AgCl}$ electrodes in control samples, samples treated with non-CoHu and $\mathrm{CoHu}$ for $2 \mathrm{~min}$. In all three groups of samples, redox potential was measured for 10 min continuously and once in an hour during $2 \mathrm{~h}$ after treatment, with humid airstream at $21^{\circ} \mathrm{C}$. Measurements were repeated with intervals of $5-10 \mathrm{~min}$.

\subsection{Surface Tension Measurement}

Surface tension of water samples was measured by using the KSV Instruments Sigma 702 ET tensiometer using the ring method. Surface tension was calculated based on the 
maximum tension at the moment when a platinum-iridium ring, being slowly pulled out of the liquid sample, broke the surface. Surface tension measurements were repeated 3 times for each group of samples. CoHu or non-CoHu were applied to $20 \mathrm{~mL}$ water samples during $5 \mathrm{~min}$.

\subsection{Dielectric Constant Measurement}

Dielectric constant in pure water and mineral waters, along with samples treated with $\mathrm{CoHu}$ and non-CoHu, was measured using the Brookhaven Instruments BI 870 dielectric constant meter at $25^{\circ} \mathrm{C}$ with $2 \%$ accuracy at $10 \mathrm{kHz}$. The measurements were repeated 3 times for each group of samples and controls. Treatment with $\mathrm{CoHu}$ or non-CoHu was in $10 \mathrm{~mL}$ liquid samples during $2 \mathrm{~min}$.

\section{6. $\mathrm{pH}$ Measurements}

Ultra-pure water was obtained as described above. Sodium bicarbonate, $\mathrm{HCl}, \mathrm{NaOH}$, $\mathrm{Na}_{2} \mathrm{HPO}_{4}$ and $\mathrm{NaH}_{2} \mathrm{PO}_{4}$ were purchased from Sigma-Aldrich (St. Louis, MO, USA).

This experiment had a goal to access the ability of $\mathrm{CoHu}$, the humid air irradiated with IR electromagnetic frequency, to affect buffer capacity of water and buffer solutions. We used pure water, $0.01 \mathrm{M}$ bicarbonate buffer with $\mathrm{pH} 8.2$ and $0.05 \mathrm{M}$ phosphate buffer with $\mathrm{pH}$ 7.0. Ultra-pure water was obtained as described above. Sodium bicarbonate, $\mathrm{HCl}$, $\mathrm{NaOH}, \mathrm{Na}_{2} \mathrm{HPO}_{4}$ and $\mathrm{NaH}_{2} \mathrm{PO}_{4}$ were purchased from Sigma-Aldrich (USA).

Ten $\mathrm{mL}$ of a buffer was put into a glass beaker with a magnet, and the beaker was placed on a magnetic mixer. Experimental and control samples were treated with $\mathrm{CoHu}$ or with non-CoHu for either 1 or $3 \mathrm{~min}$. Samples were treated with air-humidity using the blowing method without immersing a cannula into the liquid.

Bicarbonate buffer was prepared by dissolving $0.84 \mathrm{~g}$ of $\mathrm{NaHCO}_{3}$ in $1000 \mathrm{~mL}$ of distilled water. Tests were carried out with each group of samples separately. A $150 \mu \mathrm{L}$ portion of $0.1 \mathrm{M} \mathrm{HCl}$ was added to $0.01 \mathrm{M}$ bicarbonate buffer solution and 30-40 s later, $\mathrm{pH}$ value was registered with a $\mathrm{pH}$-meter Ekspert-001-3pH (Ekoniks-Ekspert, Moscow, Russia) (equipped with combined platinum/ $\mathrm{AgCl}$ electrodes). Then, the next portion of $\mathrm{HCl}$ was added. This procedure was continued until 10-11 portions of $\mathrm{HCl}$ were added. In another set of tests, $0.1 \mathrm{M} \mathrm{NaOH}$ was used for titration. This type of experiment was repeated with $0.05 \mathrm{M}$ phosphate buffer with $\mathrm{pH} 7.0$, and portions of $\mathrm{HCl}$ and $\mathrm{NaOH}$ were per $750 \mu \mathrm{L}$. A part of the samples that was treated with $\mathrm{CoHu}$ and non-CoHu was not used in titration immediately, but in 24,48 and $72 \mathrm{~h}$ after treatment.

\subsection{Data Processing}

Data were collected and analyzed with a PC equipped with Windows 7 Professional software, Microsoft Office Excel 2010 (Microsoft Corp., Redmond, WA, USA), Statistica 10 (Statsoft, Tulsa, OK, USA) and Minitab 17 (Minitab Ltd., Coventry, UK).

\section{Results}

\subsection{Redox Potentials Measurements in Pure and Mineral Waters}

Figure 2 illustrates the effect of "blowing" of humid airstream upon water surface of pure water, Senezhskaya and BioVita on their redox potentials. Bubbling of humid air led to either irreproducible or no significant effect, presumably because of excessive perturbation of the aqueous medium. For the same reason, the treatment time was reduced to 2 min in the course of preliminary tests. Redox potential was measured for 10 min continuously, and then the electrode was removed and immersed again into the sample 1 and $2 \mathrm{~h}$ after treatment with humid airstream. Control samples were not treated. Comparison of initial redox potential data in different waters shows that pure water has lower redox potential compared to Senezhskaya and BioVita. Samples that were treated with CoHu for 2 min had lower redox potential in all types of water, and this trend remained the same during the whole period of measurements. Treatment with non-CoHu increased redox potential in Senezhskaya and BioVita waters in comparison to respective controls, while in pure water, 
it resulted in a slight decrease. In Senezhskaya water, redox potential did not differ in pure water and in samples treated with non-CoHu 1 and $2 \mathrm{~h}$ after treatment, while according to the Mann-Whitney test, there was significant difference between potentials in these waters and water treated with $\mathrm{CoHu}$.

Table 1. Mean surface tension and standard deviation of the mean in pure water, Senezhskaya and BioVita mineral waters in samples that were treated by $\mathrm{CoHu}$, non-CoHu and untreated control.

\begin{tabular}{cccc}
\hline & Control & CoHu & Non-CoHu \\
\hline Pure Water Mean, $\sigma$ & 70.29 & 70.16 & 70.28 \\
\hline Pure Water $\sigma$, SD & 0.047 & 0.044 & 0.038 \\
\hline Senezhskaya Mean, $\sigma$ & 73.72 & 73.66 & 73.81 \\
\hline Senezhskaya $\sigma$, SD & 0.048 & 0.042 & 0.036 \\
\hline BioVita Mean, $\sigma$ & 73.18 & 73.09 & 73.18 \\
\hline BioVita $\sigma$, SD & 0.04 & 0.047 & 0.045 \\
\hline
\end{tabular}
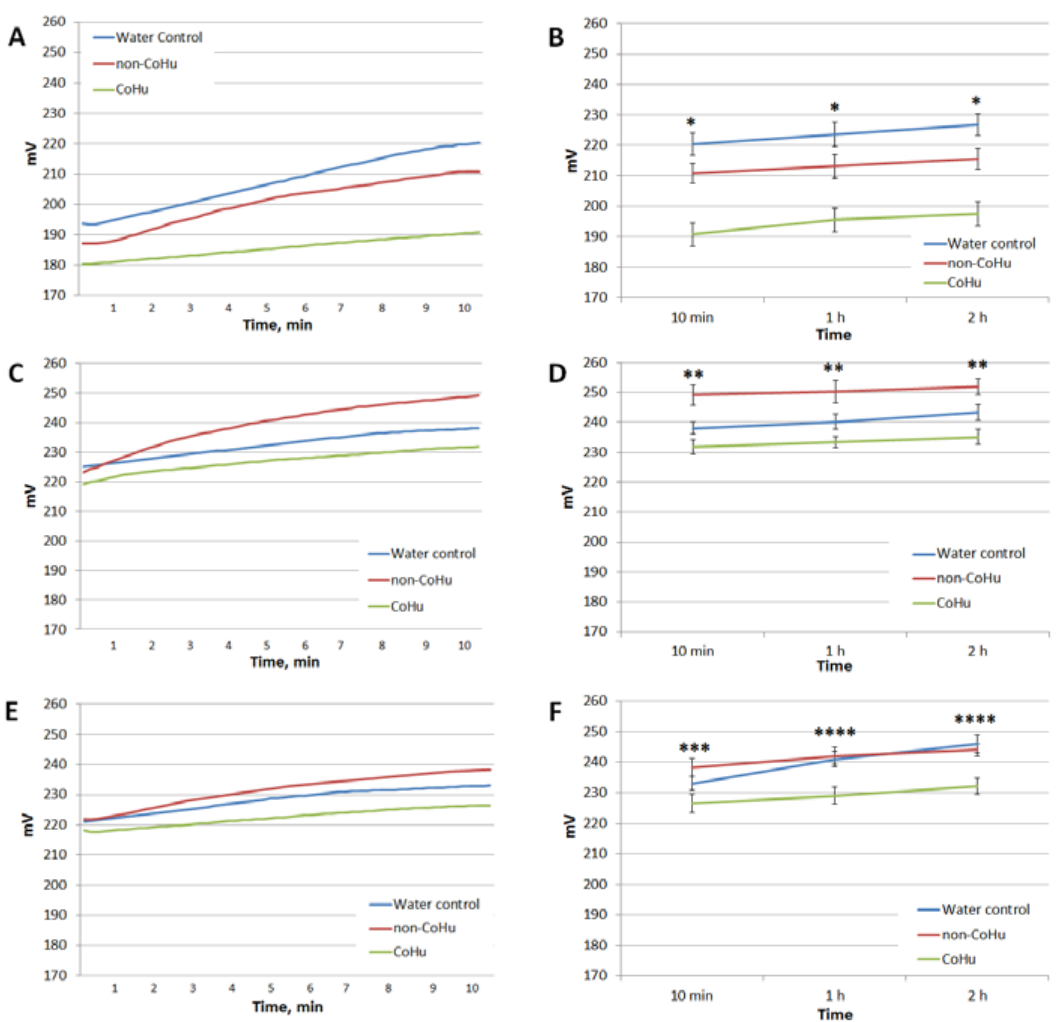

Figure 2. (A) A typical continuous measurement of redox potential in pure water in control samples (blue lines), samples Table 1. min after treatment. (B) Mean redox potential data recorded 1 and $2 \mathrm{~h}$ after treatment are presented. ${ }^{*} p<0.05$ between the three groups of samples by paired comparison by Mann-Whitney U-test. (C) A typical continuous measurement of redox potential in BioVita. (D) Mean redox potential data in BioVita recorded 1 and $2 \mathrm{~h}$ after treatment. ${ }^{* *} p<0.05$ samples treated with CoHu differ from the two other groups. (E) A typical continuous measurement of redox potential in Senezhskaya mineral bottled water. (F) Mean redox potential data in Senezhskaya recorded 1 and $2 \mathrm{~h}$ after treatment. ${ }^{* *} p<0.05$ samples of all groups significantly different from each other, ${ }^{* * * *} p<0.05$ samples treated with $\mathrm{CoHu}$ differ from the two other groups.

\subsection{Surface Tension Measurement}

Surface tension was measured in 5 parallel samples for each of the 3 groups in pure water, Senezhskaya and BioVita waters. The results are shown in Table 1. In all water samples, surface tension was unchanged after treatment with non-CoHu for $3 \mathrm{~min}$. Treatment 
with $\mathrm{CoHu}$ led to a slight decrease in surface tension values in all three types of water, especially in BioVita.

According to Fisher pairwise comparisons, mean surface tension in pure water and BioVita controls was significantly different from that of samples treated with $\mathrm{CoHu}$. In Senezhskaya water, the difference was not significant enough. In all water types, there was a reliable difference between samples treated with $\mathrm{CoHu}$ and non-CoHu. In neither type of water were differences considered significant between control untreated samples and non-CoHu-treated samples. The data analysis is shown in Figure 3.
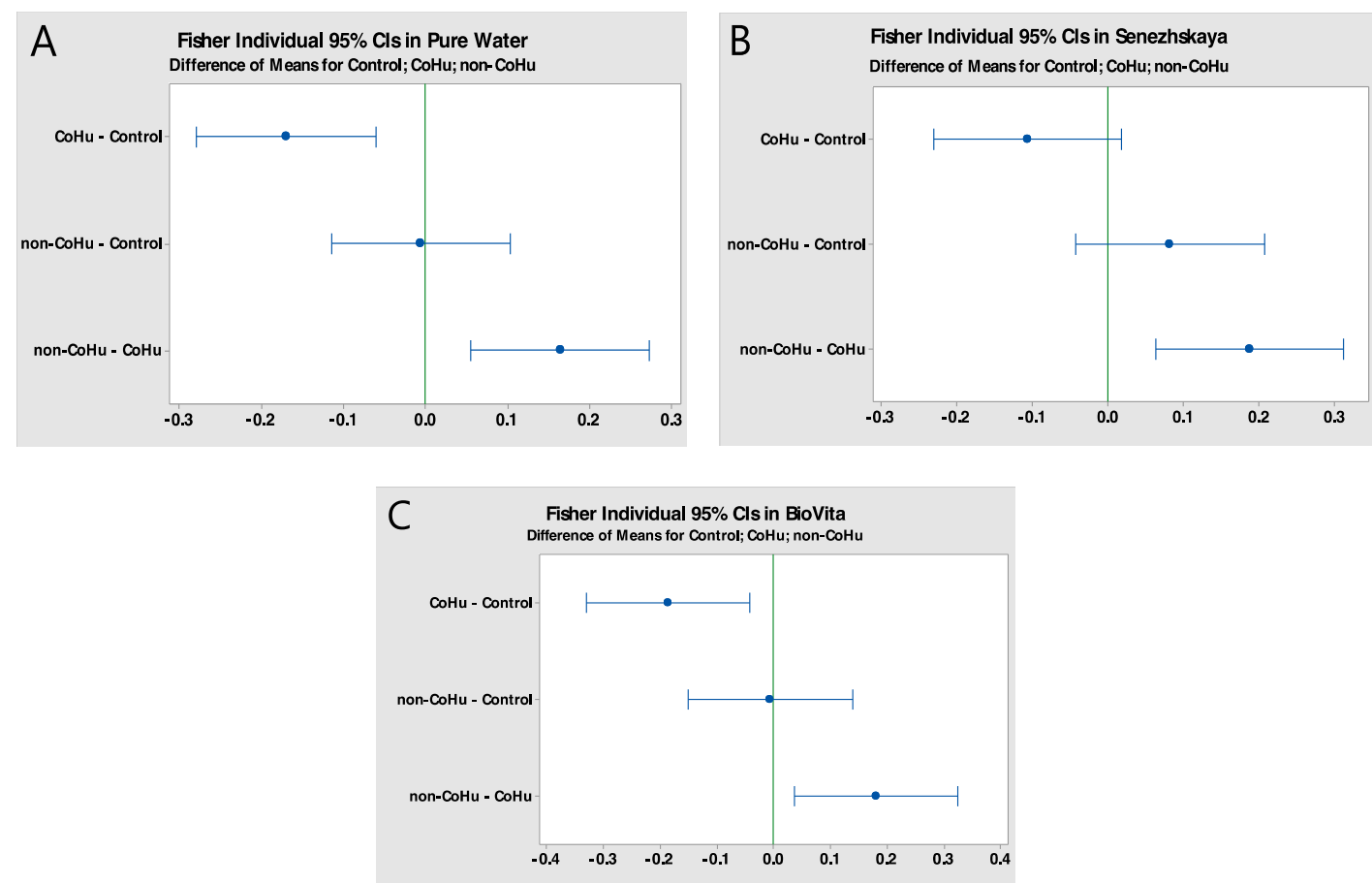

Figure 3. Fisher pairwise comparisons for surface tension measurements in pure water (A), Senezhskaya (B) and BioVita (C) mineral waters, where CIs are confidence intervals. If an interval does not contain zero, the corresponding means are significantly different.

\subsection{Dielectric Constant Measurement}

The static dielectric constant of pure water is around 81 due to the fact that water is a strongly polar liquid; however, its molecules have a degree of freedom and rotation. Each water molecule has a significant dipole moment. In the absence of an electric field, the dipoles are oriented randomly, and the total electric field created by them is equal to zero. If water is placed in an electric field, then the dipoles will begin to reorient themselves so as to weaken the applied field. Such a picture is observed in other polar liquids, but water, due to the large value of the dipole moment of $\mathrm{H}_{2} \mathrm{O}$ molecules, is capable of a very strong (around 80 times) weakening of the external field. Thus, dielectric constant reflects the capability of water to react to external electromagnetic fields. In the presence of solvents, it slightly varies.

Figure 4A presents dielectric constant measurement data and Fisher pairwise comparisons for pure water control samples, samples treated with $\mathrm{CoHu}$ and non-CoHu (Figure 4B). Dielectric constant increased in samples that were treated with $\mathrm{CoHu}$ and did not significantly differ in samples that were treated with non-CoHu according to the MannWhitney U-test. A very similar pattern was observed in Senezhskaya water (Figure 5B) and BioVita (Figure 6B). In both these cases, treatment with $\mathrm{CoHu}$ significantly increased the dielectric constant. However, according to Fisher pairwise comparisons, means are different in all pairs in pure water and Senezhskaya (Figures 5B and 6B). In BioVita, mean 
dielectric constant values did not differ significantly between control and samples treated with non-CoHu (Figure 6B).
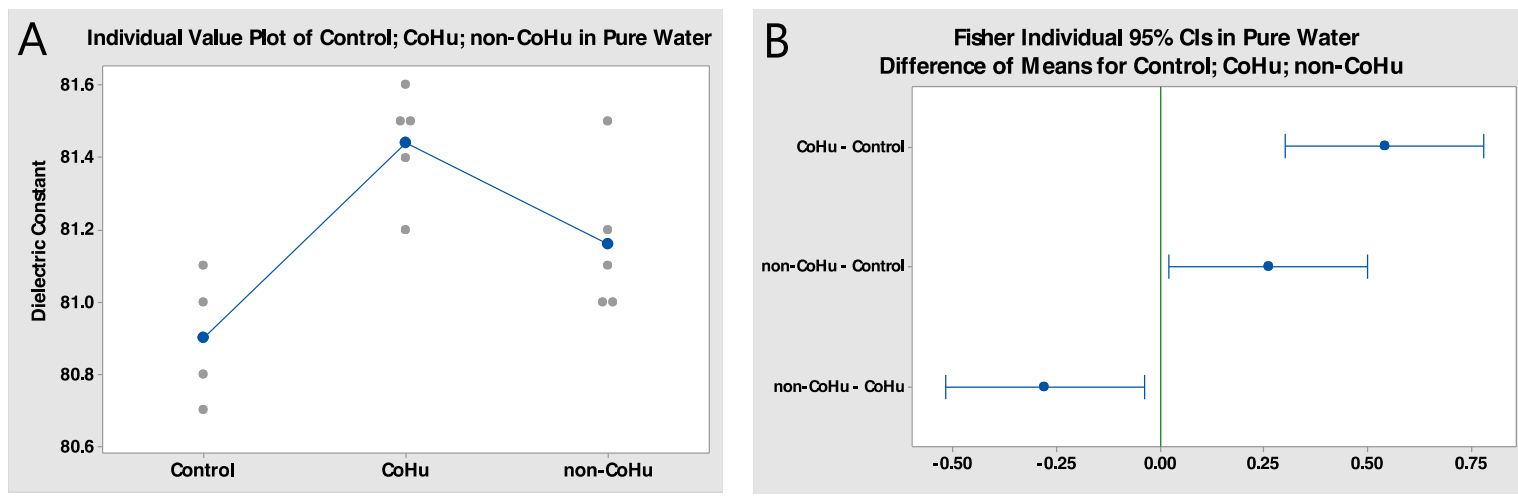

Figure 4. (A) Pure water dielectric constant scattered data in samples treated with $\mathrm{CoHu}$ and non-CoHu. (B) Fisher pairwise comparisons for dielectric constant measurements in pure water. CIs are confidence intervals. If an interval does not contain zero, the corresponding means are significantly different.
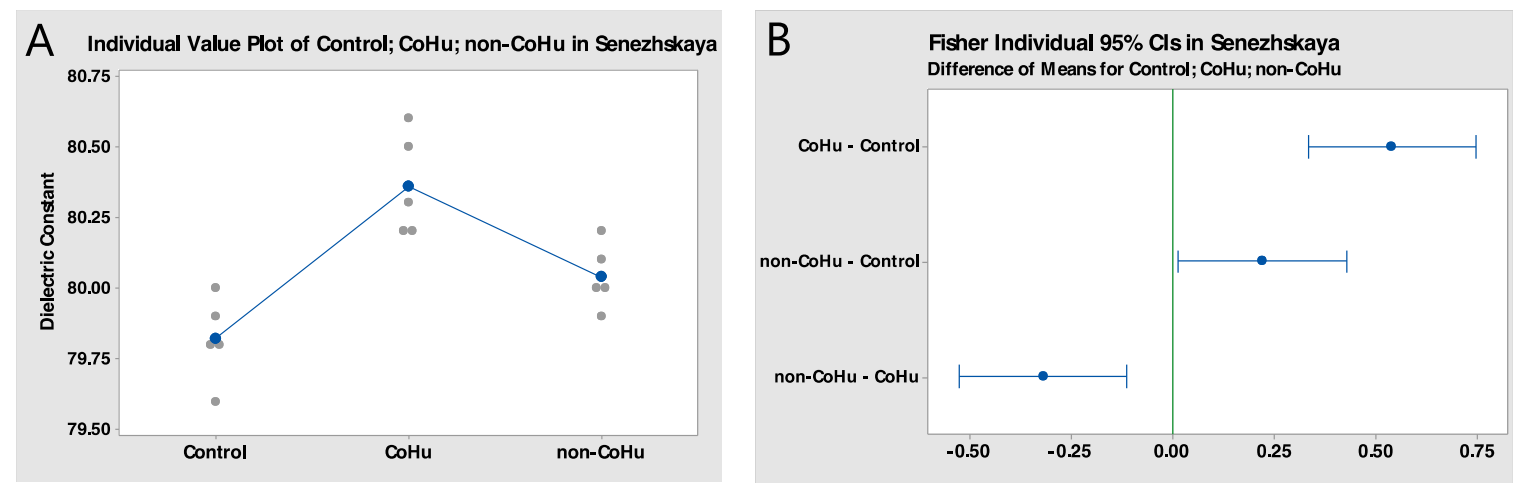

Figure 5. (A) Senezhskaya water dielectric constant scattered data in samples treated with CoHu and non-CoHu. (B) Fisher pairwise comparisons for dielectric constant measurements in Senezhskaya natural water. CIs are confidence intervals. If an interval does not contain zero, the corresponding means are significantly different.
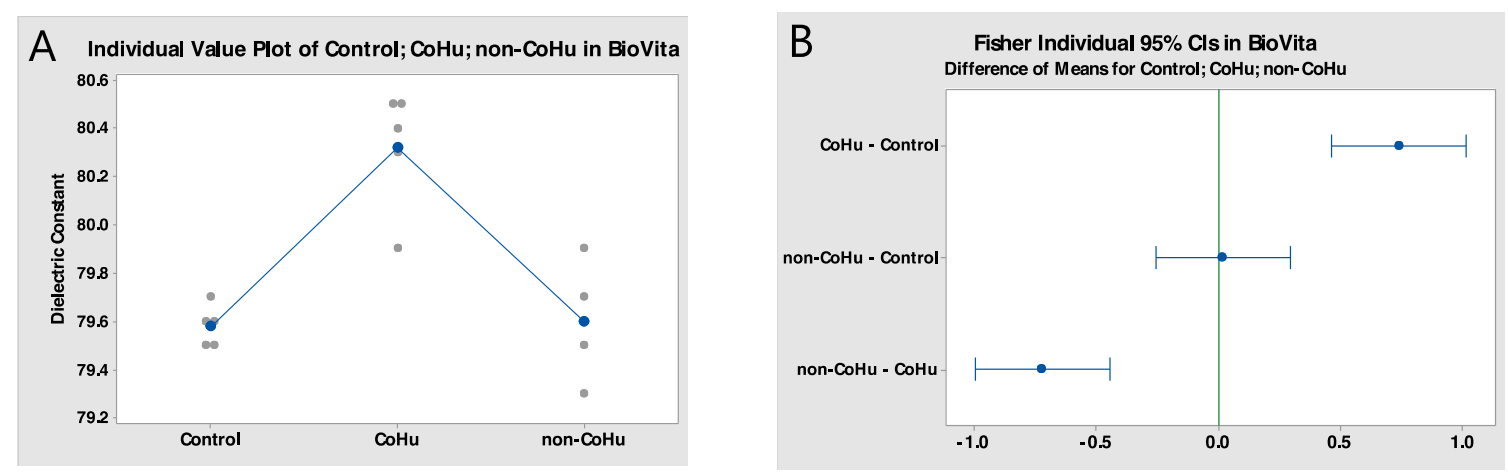

Figure 6. (A) BioVita water dielectric constant scattered data in samples treated with $\mathrm{CoHu}$ and non-CoHu. (B) Fisher pairwise comparisons for dielectric constant measurements in BioVita natural water. CIs are confidence intervals. If an interval does not contain zero, the corresponding means are significantly different.

\section{4. $\mathrm{pH}$ Measurement}

Figure 7 represents typical results of $\mathrm{pH}$ measurement in bicarbonate buffer that was titrated with $0.1 \mathrm{~mol} / \mathrm{L} \mathrm{HCl}$ or $0.1 \mathrm{~mol} / \mathrm{L} \mathrm{NaOH}$. Graphs also show $\mathrm{pH}$ values for titration of buffer samples that were treated with $\mathrm{CoHu}$ for $3 \mathrm{~min} 24 \mathrm{~h}$ before titration. In case of titration with $\mathrm{HCl}, \mathrm{pH}$ started to drop after the 7th portion of $\mathrm{HCl}$ in control samples and 
samples that were treated with non-CoHu, while in samples that were treated with $\mathrm{CoHu}$ for 1 or $3 \mathrm{~min}, \mathrm{pH}$ started to drop after the 8th or the 9th portion. In the case of titration with $\mathrm{NaOH}, \mathrm{pH}$ began to rise in samples that were treated with $\mathrm{CoHu}$ after addition of one or two portions, more than it did in control samples and samples treated with non-CoHu. Titrations with $\mathrm{HCl}$ and $\mathrm{NaOH}$ were repeated 4 times for all groups of samples. In the case of titration with $\mathrm{HCl}, \mathrm{pH}$ values in samples treated with $\mathrm{CoHu}$ after the addition of the 8th and 9th portion significantly differed from control samples and samples treated with non-CoHu according to the Mann-Whitney test, with $p=0.0128$ and 0.0117 , respectively. Similarly, in the case of titration with $\mathrm{NaOH}$, $\mathrm{pH}$ values in samples treated with $\mathrm{CoHu}$ significantly differed on the addition of the 7th and 8th portion of alkali from control samples and samples treated with non-CoHu, with $p=0.0376$ and 0.0202 , respectively. After addition of the 9th portion of $\mathrm{NaOH}, \mathrm{pH}$ data was reliably different between samples that were treated with $\mathrm{CoHu}$ for $3 \mathrm{~min}$ before titration and $24 \mathrm{~h}$ before titration $(p<0.05)$. $\mathrm{pH}$ values in control samples and samples treated with non-CoHu did not differ.
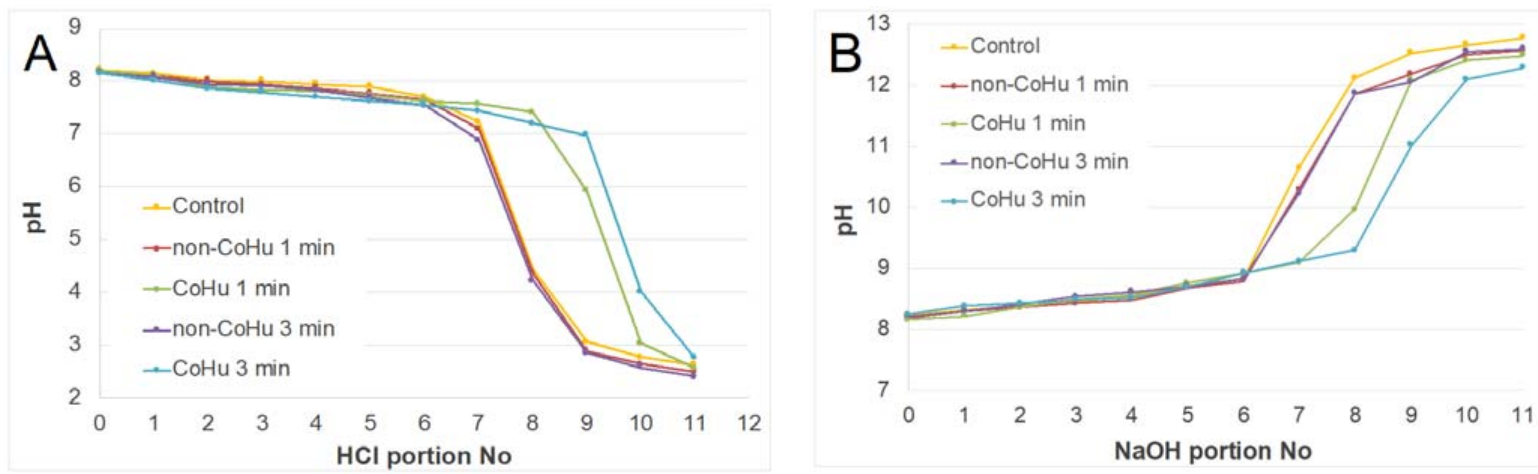

Figure 7. (A) A typical curve of titration of $0.01 \mathrm{M}$ bicarbonate buffer treated with $\mathrm{CoHu}$ or non-CoHu with $0.1 \mathrm{M} \mathrm{HCl}$ and (B) with $0.1 \mathrm{M} \mathrm{NaOH}$. Some samples were treated with the airstream for $3 \mathrm{~min}$.

In a parallel experiment, $\mathrm{pH}$ was measured in the course of titration either with $\mathrm{HCl}$ or $\mathrm{NaOH}$ of buffer samples that were treated with $\mathrm{CoHu}$ or non-CoHu immediately before titration and 1-3 days prior to it. The results with statistical errors are presented in Figures 8 and 9 along with Mann-Whitney U-test probability analysis.

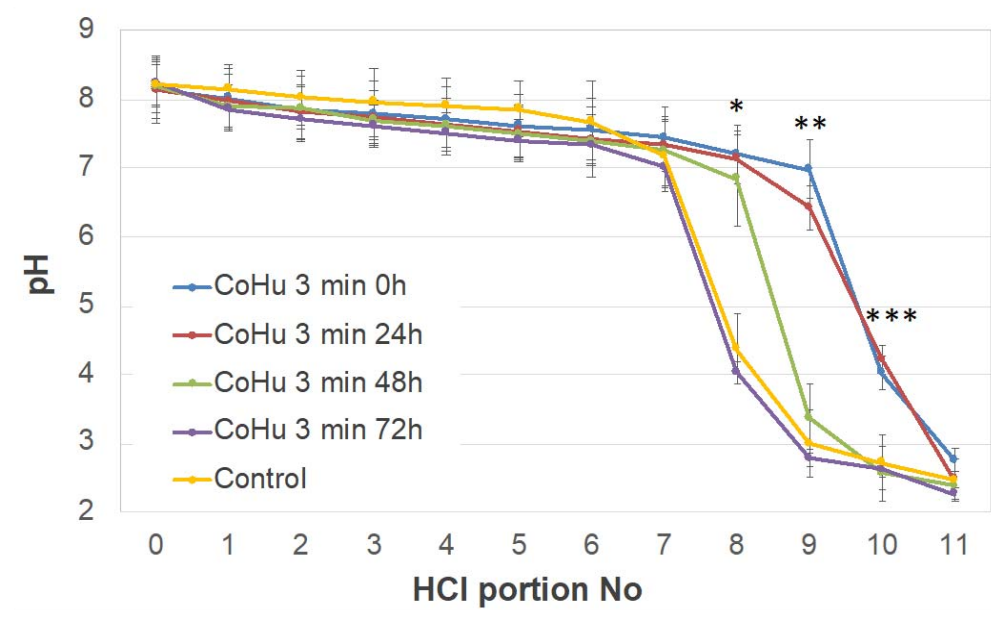

Figure 8. Averaged 0.01 M bicarbonate buffer titration curves with $0.1 \mathrm{M} \mathrm{HCl}$. Samples were treated with $\mathrm{CoHu}$ for $3 \mathrm{~min}$ immediately before titration, 24,48 and $72 \mathrm{~h}$ before titration. ${ }^{*} p<0.01$ between control and samples that were treated with $\mathrm{CoHu} 0,24$ and $48 \mathrm{~h}$ before treatment; ${ }^{* *},{ }^{* * *} p<0.01$ between united control and samples that were treated with $\mathrm{CoHu} 48 \mathrm{~h}$ before treatment and samples that were treated with $\mathrm{CoHu} 0$ and $24 \mathrm{~h}$ before treatment. 


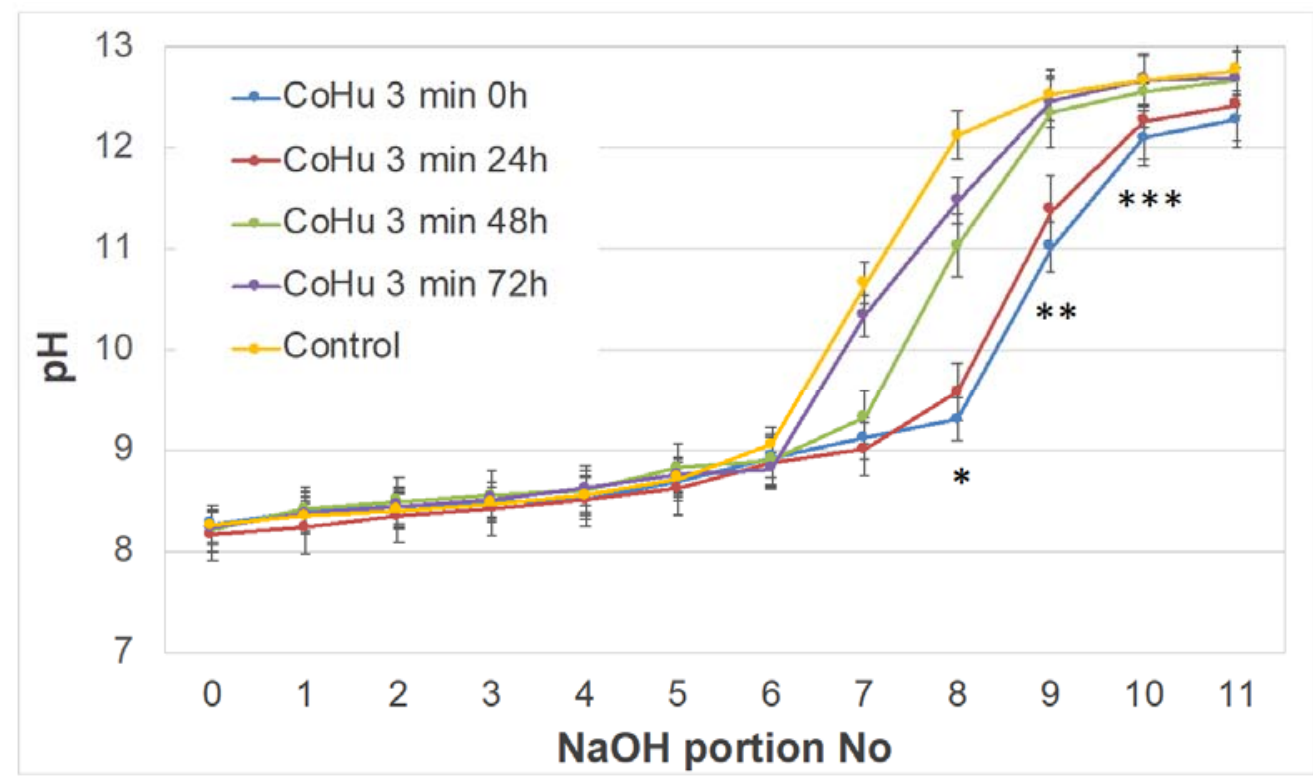

Figure 9. Averaged 0.01 M bicarbonate buffer titration curves with $0.1 \mathrm{M} \mathrm{NaOH}$. Samples were treated with CoHu for $3 \mathrm{~min}$ immediately before titration, 24,48 and $72 \mathrm{~h}$ before titration. ${ }^{*},{ }^{* *} p<0.01$ between samples that were treated with $\mathrm{CoHu}$ immediately and $24 \mathrm{~h}$ before treatment and united control samples and samples that were treated with $\mathrm{CoHu} 48$ and $72 \mathrm{~h}$ before treatment; ${ }^{* * *} p<0.05$ between control and samples that were treated with CoHu immediately before treatment.

Very similar results were obtained with phosphate buffer (Figure 10). In case of titration with portions of $0.1 \mathrm{M} \mathrm{HCl}$ in samples treated with $\mathrm{CoHu}, \mathrm{pH}$ began to drop 2 or 3 portions later than it did in control samples. Values of $\mathrm{pH}$ remained more stable in samples that were treated for $3 \mathrm{~min}$. This effect cannot be attributed to any impact of the airflow as $\mathrm{pH}$ change pattern in samples that were treated with non-coherent humid air (non-CoHu) is undistinguishable from controls. Four titrations both with $\mathrm{HCl}$ and $\mathrm{NaOH}$ were performed.
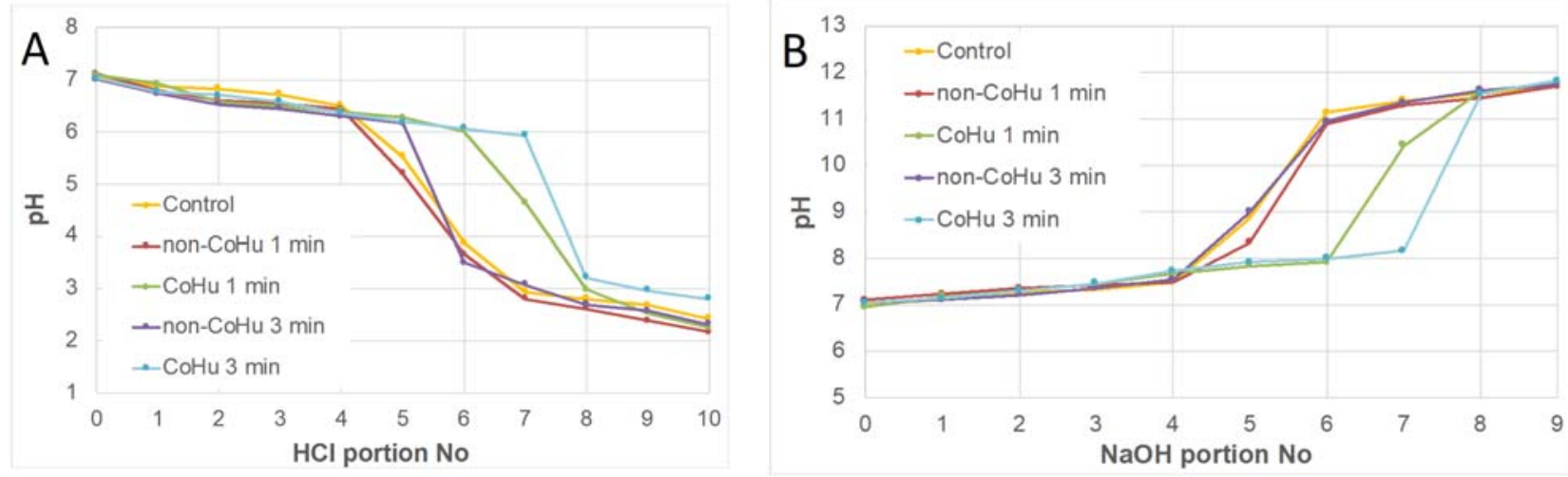

Figure 10. Typical curve of titration of $0.05 \mathrm{M}$ phosphate buffer treated with $\mathrm{CoHu}$ or non-CoHu with $0.1 \mathrm{M} \mathrm{HCl}(\mathrm{A})$ and with $0.1 \mathrm{M} \mathrm{NaOH}(\mathbf{B})$. Some samples were treated with the airstream for 1 or $3 \mathrm{~min}$.

\section{Discussion}

According to our knowledge, we examined the effect of coherent humid air on such parameters of the aqueous medium as oxidation-reduction potential, changes in $\mathrm{pH}$ with the addition of acid or alkali, surface tension and dielectric constant for the first time. Deionized pure water, two types of mineral waters and buffers were the examples of aqueous systems that were considered as test systems to determine possible effects of $\mathrm{CoHu}$ for its potential future application to biological objects, for agricultural and medical 
purposes. A feature of our experiments is that the water systems were not directly irradiated with infrared light, but aqueous aerosol was used as an intermediary.

Aqueous aerosol, or humid air, produced by a compressor-type evaporator, was treated with IR radiation $(\mathrm{CoHu})$ or was not treated (non-CoHu) for control. This allowed to perform tests with an appropriate control treatment on the impacts of the airstream, shaking and heating, while sample treatments were equal both in test and control samples, which is important for such study that requires accuracy to detect subtle effects.

The volumes of water samples treated with $\mathrm{CoHu}$ or non-CoHu were 10 and $20 \mathrm{~mL}$, depending on the method of measurement. In both cases, the surface area to volume ratio was approximately the same, however the study of the effects of volume and surface area is worthy of a separate study.

Redox potential was measured in pure water and the two types of mineral watersSenezhskaya and BioVita (Figure 2). Untreated control pure water had lower redox potential compared to untreated control mineral waters. Treatment of all types of water with $\mathrm{CoHu}$ for $2 \mathrm{~min}$ led to a redox potential decrease in all types of water, and this trend remained the same during the whole measurement. In samples that were treated with non- $\mathrm{CoHu}$, redox potential increased in Senezhskaya and BioVita waters, while in pure water, a slight decrease was observed. The redox potential decrease indicates that water treated with $\mathrm{CoHu}$ may possess antioxidant properties. The redox potential of the aqueous medium in living organisms is usually lower than in environmental water. Interestingly, redox potential of EZ water formed at the surface of hydrophilic powder also showed a decrease [11]. The development of a negative electric potential of -120 to $-160 \mathrm{mV}$ across the boundary between the exclusion zone formed at the Nafion ${ }^{\circledR}$ surface and bulk water (EZ-water is negatively charged) was reported in the context of EZ-water studies [9]. The charge separation occurred immediately as the EZ was formed and protons were excluded from it.

After treatment of pure water (Figure 4), Senezhskaya (Figure 5) and BioVita (Figure 6) waters with $\mathrm{CoHu}$, a tendency for the increase of the dielectric constant in all these waters was observed. Fisher pairwise comparison showed also that in pure water and Senezhskaya water, both $\mathrm{CoHu}$-treated samples and non-CoHu-treated samples had higher mean dielectric constant values. In BioVita water, both $\mathrm{CoHu}$-treated samples and non-CoHutreated samples differed from untreated water however they did not differ from each other. Dielectric constant indicates the ability of the liquid to weaken the external field. Pure and mineral waters interact with the field and weaken it almost 80 times. The increase of the dielectric constant was slight, though may be indicative of the increased charge storage capacity and the dipole moment of the whole sample or some zones in them.

It should be noted that tap water in which surface tension reaches $\sim 75 \mathrm{dyn} / \mathrm{cm}$ hardly supports metabolism in living organisms and in cells. A cell is capable to use water having surface tension of $\sim 43-45 \mathrm{dyn} / \mathrm{cm}$ ( $45 \mathrm{dyn} / \mathrm{cm}$ is a biologically optimal surface tension of the tissue fluid and blood) [18]. Surface tension decreased in all types of waters after treatment with $\mathrm{CoHu}$ (Table 1), which is in line with [11] as the density of coherent water is approximately $0.97 \mathrm{~g} / \mathrm{cm}^{3}$, as coherent water molecules take up more space. In samples that were treated with non- $\mathrm{CoHu}$, no change in surface tension was observed, so the impact of "blowing" of the airstream upon the sample surface should be considered (Figure 3). More research is needed to determine whether the density is heterogenous or not in the samples treated with $\mathrm{CoHu}$.

The character of $\mathrm{pH}$ change in $\mathrm{CoHu}$-treated bicarbonate and phosphate buffer in response to the addition of portions of alkali or acid allows to suggest the ability of $\mathrm{CoHu}$ to alter buffer capacity of aqueous systems. Interestingly, this effect did not depend on whether CoHu was applied for 1 or $3 \mathrm{~min}$. Moreover, this effect persisted for $48 \mathrm{~h}$ after treatment with $\mathrm{CoHu}$. If it is suggested that $\mathrm{CoHu}$ acts as a source of $\mathrm{EZ}$ or as a factor providing for its formation in treated water, it can be assumed that the effect on the buffer properties of solutions is associated with the separation of negative and positive charges. We have already demonstrated that in highly diluted hydrated fullerene C60 
solutions prepared using vigorous agitation at each step, $\mathrm{pH}$ response to the addition of $\mathrm{HCl}$ demonstrates an increase in buffering capacity in comparison with control [19]. In the same study, we observed structural heterogeneity in samples with highly diluted hydrated fullerene. This corresponds with data obtained in the laboratory of Elia, who have demonstrated that homeopathic remedies such as Arnica Montana, Arsenicum Album and Magnesium Muriaticum have higher capability to buffer $\mathrm{pH}$ decrease when they are titrated with $\mathrm{HCl}$ than water used for the preparation of these solutions [20]. The authors suggested that excessive buffering capacity was provided by supramolecular organization occurring in the extremely diluted solutions, namely by the appearance in them of dissipative coherent water structures in the course of serial dilutions with intensive shaking.

Thus, water, either liquid or gaseous, has a potential to form unstable aggregates. Del Giudice and Preparata [21,22] suggested a quantum-physics-based model that involved the presence of 100 nanometers large coherent domains (CDs) in liquid water. Del Giudice and colleagues [23-25] saw similarities between EZ-water and coherent domains, although Pollack [26] has proposed a different structure and origin for EZ-water. The surface charge of the EZ was suggested to depend on the surface charge of the hydrophilic surface on which it is formed, thus positively charged hydrophilic gels promote a positive charge at the surface of the EZ with a high $\mathrm{pH}$ zone [27].

Conventional quantum electrodynamic (QED) field theory applies only to gases, however Del Giudice and Preparata expanded it to the condensed phase of liquids. According to QED theory, two substances are formed in water in order to minimize potential energyCDs and common bulk water. In a CD, all water molecules are in a coherent state with in-phase wave functions. As a result, the overall wave function of the entire domain is a million times magnified wave function of any of the individual water molecules in the domain [28].

The CD contains a large number of quasi free electrons. The reason for this lies in the fact that the energy of the excited state of the $\mathrm{CD}$ is $12.06 \mathrm{eV}$, which is very close to the ionization energy of water molecules of $12.6 \mathrm{eV}$ [29]. Therefore, water in $\mathrm{CD}$ can serve as a donor of electrons, which participate in redox processes, and this is in line with the findings of this paper. Emerging and reforming CDs surrounded by bulk incoherent water may play a particular role in the biological functions of water [30-33].

In a study on aerosols formed at waterfalls, Madl et al. have shown [34] the presence of negatively charged nanometer-sized and up to $100 \mathrm{~nm}$ large water clusters that contain millions of water molecules. Unlike unstable small clusters, large water aggregates can be found hundreds of meters away from the waterfall. Both negative surface charge and the size are in accordance with the QED theory of water developed by Del Giudice and colleagues [25]. The authors suggest that the river flow offers conditions for formation of CDs made up by both positively and negatively charged entities. Then, it becomes fragmented by the waterfall, acquires a portion of energy and the CDs become separated in the form of an aerosol. Thus, these aerosol water clusters can act as a surface, and exposure to IR is expected to cause the growth of these clusters in humid conditions.

Water clusters can make crucial contributions to the IR absorption spectrum of water vapor [35]. Moreover, infrared absorption of water vapor is related to ion-production in vapor and electrical properties of air, which also fits into the concept of charged surfaces and charge separation during the formation of CDs and EZ-water. Carlson's suggestion that the hydronium ion could be implicated in the absorption at 3-5 $\mu \mathrm{m}$ observed in water vapor measurements also implies charge separation in vapor [36].

Using the methods of dynamic light scattering, nanoparticle tracking analysis (NTA) and transmission electron microscopy (TEM), it was possible to experimentally show the existence of nanoscale self-regulating molecular ensembles in aqueous systems, nanoassociates, with sizes of $100-400 \mathrm{~nm}$ and a $\zeta$-potential from -2 to $-20 \mathrm{mV}[37,38]$. A necessary condition for their formation is the presence of traces of impurities in the water and the presence of external electromagnetic fields. According to the research data of other 
authors, from the standpoint of QED, it is possible to assume the formation of nanoscale CDs in the presence of external fields in an aqueous medium [39].

A noteworthy NMR study [40], where proton relaxation times $T_{1}$ (the spin-lattice relaxation time) and $T_{2}$ (the spin-spin relaxation time) were measured in distilled water, homeopathic remedy, spring water and water treated with electromagnetic fields, demonstrated evidence of the presence of supramolecular structures similar to liquid crystals, whose molecules are arranged in some order and whose state of matter is between that of a liquid and a crystalline solid. The authors suggest that their findings could be explained from the point of the hypothesis of CDs and EZ-water formation.

Messori et al. provided a holistic overview of the role and physical mechanisms of action of EZ and CDs in living organisms, where EZ is regarded as long-range ensembles of CDs [40]. They focused on phase transition of water from the ordinary coherence of its liquid state (bulk water, as water cannot be completely incoherent) to the semi-crystalline state of interfacial water and its role in living organisms, where electron/proton dynamics and response to electromagnetic fields are used to receive electromagnetically encoded signals endowed with coherence at a low frequency. The resultant excitations are summed, and the coherence is distributed at frequencies that may affect biological systems.

It has recently been shown that laser radiation induced ROS (hydrogen peroxide, hydroxyl and superoxide radicals) generation in solutions of blood serum proteins, bovine serum albumin and gamma-globulin, resulting in the formation of long-lived reactive protein species [41]. These visible light- and heat-induced long-lived reactive protein products can generate hydrogen peroxide in aqueous medium and it contributes to the adaptation of living organisms to stress factors [42]. Authors suggest that ROS generation can be related to the release of extra free energy via surface tension in air nanobubbles present in water (bubstons-bubbles stabilized by ions) as a result of their collapse under the action of visible light, laser irradiations or heat. A resonance excitation of molecular oxygen by wavelengths corresponding to its transition to singlet state leads to electromagnetic disturbance, resulting in collapse of nanobubbles. Interestingly, the size of mesoscopic droplets formed in low-concentration aqueous solutions of polar organic compounds increases with temperature [43], which also contributes to the mass of evidence of the peculiar role of heat in water solutions. We have already mentioned the work of [11], where EZ-like water was obtained by its non-contact treatment with IR-emitting QELBY ceramic powder (Quantum Energy Co Ltd., Hanam-si, South Korea) that was at temperature equilibrium with water. Thus, the authors suggest that it was not heating that changed water structure but the IR emission of the powder, which is suggested to be more coherent compared to a more chaotic IR component in environmental IR radiation associated with the ambient heat. The physicochemical characteristics of IR-altered water in this paper are supported by strong evidence of the authors of [44], who have shown that water prepared either by mixture with the ceramic powder, or which is especially noteworthy, by non-contact treatment, exhibited antioxidant properties, stimulated plant growth, increased normal cell culture viability and decreased cancer cells' viability, and also increased the cytokine expression in the splenocytes.

Hydrogen bonding, whose behavior and fluctuations depend on energetic characteristics of $\mathrm{O}-\mathrm{H}$ bond in water molecules, plays an important role in EZ-water maintenance. Thus, energy absorption by $\mathrm{O}-\mathrm{H}$ bonds can affect hydrogen bonding and EZ formation.

The question may arise as to why the humid air was treated with IR radiation, and not the liquids themselves. According to Pollack's theory [26], water microdroplets have an exclusion zone water layer on their surface, and water is spherically confined there due to surface tension at the air-water interface. Smaller droplets have a relatively larger EZ area. As it was mentioned above, EZ expands upon absorption of a sufficient amount of IR energy to modify the hydrogen bonding network in a water microdroplet. As water vapor absorbs more intensely in IR, it is used as an inducer of EZ in bulk liquid water. Moreover, irradiation of water with IR leads to its heating, and microdroplets lose obtained heat quicker. Irradiation with LED is mostly coherent and transferring of this coherent 
signal to humid air with suspended microdroplets and molecular water, when they begin to oscillate in a coherent manner, is more effective than transferring it to liquid water. If we suggest that water microdroplets uptake extra energy in the form of IR and store it in the form of EZ, when they fuse with condensed phase, they are likely to give this energy off. Another aspect comes from studies of plasma-water interactions, where the highest production of hydrogen peroxide in water was obtained by treating water microdroplets with plasma, which is known to cause reactive oxygen species generation in water [45]. This is explained by the large surface area of the vapor droplets. So, it can be assumed that microdroplets in the humid air have an increased surface-to-volume ratio and absorb well in the IR region of the spectrum, which leads to an increase in the EZ and promotes the transition of water molecules to a coherent phase. These microdroplets come into contact with the treated liquid, which leads to a change in its physicochemical parameters. To sum up, water microdroplets are more effective in exchange of IR energy than condensed water.

\section{Conclusions}

According to the results of our study, in which we investigated the changes in the physicochemical properties of aqueous systems after non-chemical treatment with humid air exposed to IR waves, we obtained a number of similarities with exclusion zone water, which were absent after treatment with untreated humid air and untreated water control. These were changes in the redox potential and dielectric constant. A change in buffer properties indicates an alteration in the distribution of positive and negative charges characteristic of EZ, and a change in surface tension indicates the presence of heterogeneity in the treated aqueous medium, which is typical of both EZ and CDs.

Author Contributions: Conceptualization, O.Y. and V.V.; methodology, O.Y.; software, E.B.; validation, A.T.; investigation, O.Y., K.N. and E.B.; resources, A.T.; writing, O.Y. and V.V.; visualization, E.B. All authors have read and agreed to the published version of the manuscript.

Funding: This research received no external funding.

Institutional Review Board Statement: Not applicable.

Informed Consent Statement: Not applicable.

Data Availability Statement: The data presented in this study are available on request from the corresponding author.

Conflicts of Interest: The authors declare no conflict of interest.

\section{References}

1. Cooke, R.; Kuntz, I.D. The properties of water in biological systems. Annu. Rev. Biophys. Bioeng. 1974, 3, 95-126. [CrossRef]

2. Ling, G.N. The physical state of water in living cell and model systems. Ann. N. Y. Acad. Sci. 1965, 125, 401-417. [CrossRef]

3. Lo, A.; Cardarella, J.; Turner, J.; Lo, S.Y. A soft matter state of water and the structures it forms. Forum. Immunopathol. Dis. Ther. 2012, 3, 237-252. [CrossRef]

4. Konovalov, A.I.; Ryzhkina, I.S. Highly diluted aqueous solutions: Formation of nano-sized molecular assemblies (nanoassociates). Geochem. Int. 2014, 52, 1207-1226. [CrossRef]

5. Ho, M.W.; Haffegee, J.; Newton, R.; Zhou, Y.M.; Bolton, J.S.; Ross, S. Organisms as polyphasic liquid crystals. Bioelectrochem. Bioenerg. 1996, 41, 81-91. [CrossRef]

6. Tokushima, T.; Harada, Y.; Takahashi, O.; Senba, Y.; Ohashi, H.; Pettersson, L.G.; Nilsson, A.; Shin, S. High resolution X-ray emission spectroscopy of liquid water: The observation of two structural motifs. Chem. Phys. Lett. 2008, 460, 387-400. [CrossRef]

7. Soper, A.K.; Ricci, M.A. Structures of high-density and low-density water. Phys. Rev. Lett. 2000, 84, 2881. [CrossRef]

8. Zheng, J.M.; Pollack, G.H. Long-range forces extending from polymer-gel surfaces. Phys. Rev. E 2003, 68, 031408. [CrossRef] [PubMed]

9. Zheng, J.M.; Chin, W.C.; Khijniak, E.; Khijniak, E., Jr.; Pollack, G.H. Surfaces and interfacial water: Evidence that hydrophilic surfaces have long-range impact. Adv. Colloid Interface Sci. 2006, 127, 19-27. [CrossRef]

10. Chai, B.; Yoo, H.; Pollack, G.H. Effect of radiant energy on near-surface water. J. Phys. Chem. B 2009, 113, 13953-13958. [CrossRef] [PubMed]

11. Hwang, S.G.; Hong, J.K.; Sharma, A.; Pollack, G.H.; Bahng, G. Exclusion zone and heterogeneous water structure at ambient temperature. PLoS ONE 2018, 13, e0195057. [CrossRef] [PubMed] 
12. Hamashima, T.; Mizuse, K.; Fujii, A. Spectral signatures of four-coordinated sites in water clusters: Infrared spectroscopy of phenol- $\left(\mathrm{H}_{2} \mathrm{O}\right) \mathrm{n}(\sim 20 \leq \mathrm{n} \leq \sim 50)$. J. Phys. Chem. A 2011, 115, 620-625. [CrossRef] [PubMed]

13. Lemus, R. Vibrational excitations in $\mathrm{H}_{2} \mathrm{O}$ in the framework of a local model. J. Mol. Spectrosc. 2004, 225, 73-92. [CrossRef]

14. Röttgers, R.; McKee, D.; Utschig, C. Temperature and salinity correction coefficients for light absorption by water in the visible to infrared spectral region. Opt. Express 2014, 22, 25093-25108. [CrossRef] [PubMed]

15. Carlon, H.R. Aerosol spectrometry in the infrared. Appl. Opt. 1980, 19, 2210-2218. [CrossRef]

16. Tiezzi, E.; Catalucci, M.; Marchettini, N. The supramolecular structure of water: NMR studies. Int J. Des. Nat. Ecodyn. 2010, 5, 10-20. [CrossRef]

17. Standard Methods for the Examination of Water and Wastewater, 20th ed.; American Public Health Association, American Water Work Association, Water Environment Federation: Washington, DC, USA, 1998.

18. Goncharuk, V.V.; Kovalenko, V.F.; Zlatskii, I.A. Comparative analysis of drinking water quality of different origin based on the results of integrated bioassay. J. Water Chem. Technol. 2012, 34, 61-64. [CrossRef]

19. Voeikov, V.; Yablonskaya, O.; Buravleva, E.; Novikov, K. Peculiarities of the physicochemical properties of hydrated C60 fullerene solutions in a wide range of dilutions. Front. Phys. 2021, 9, 64.

20. Elia, V.; Napoli, E.; Niccoli, M. Physical-chemical study of water in contact with a hydrophilic polymer: Nafion. J. Therm. Anal. Calorim. 2013, 112, 937-944. [CrossRef]

21. Arani, R.; Bono, I.; Del Giudice, E.; Preparata, G. QED coherence and the thermodynamics of water. Int. J. Mod. Phys. B 1995, 9 , 1813-1841. [CrossRef]

22. Del Giudice, E.; Preparata, G. Coherent electrodynamics in water. In Fundamental Research in Ultra High Dilution and Homoeopathy; Schulte, J., Endler, P.C., Eds.; Springer: Dordrecht, The Netherlands, 1998; pp. 89-103.

23. Del Giudice, E.; Spinetti, P.R.; Tedeschi, A. Water dynamics at the root of metamorphosis in living organisms. Water 2010, 2, 566-586. [CrossRef]

24. Del Giudice, E.; Tedeschi, A.; Vitiello, G.; Voeikov, V. Coherent structures in liquid water close to hydrophilic surfaces. J. Phys. Conf. Ser. 2013, 442, 012028. [CrossRef]

25. Capolupo, A.; Del Giudice, E.; Elia, V.; Germano, R.; Napoli, E.; Niccoli, M.; Tedeschi, A.; Vitiello, G. Self-similarity properties of nafionized and filtered water and deformed coherent states. Int. J. Mod. Phys. B 2014, 28, 1450007. [CrossRef]

26. Pollack, G.H. The Fourth Phase of Water; Ebner \& Sons Publishers: Seattle, DC, USA, 2013.

27. Zheng, J.M.; Wexler, A.; Pollack, G.H. Effect of buffers on aqueous solute-exclusion zones around ion-exchange resins. J. Colloid Interface Sci. 2009, 332, 511-514. [CrossRef] [PubMed]

28. Del Giudice, E.; Preparata, G.; Vitiello, G. Water as a free electric dipole laser. Phys. Rev. Lett. 1988, 61, 1085. [CrossRef]

29. Voeikov, V.; Korotkov, K. Novaya Nauka o Vode; Mednii Vsadnik: St. Petersburg, Russia, 2017; pp. 67-70. (In Russian)

30. Del Giudice, E. Old and new views on the structure of matter and the special case of living matter. J. Phys. Conf. Ser. 2007, 67, 012006. [CrossRef]

31. Del Giudice, E.; Vitiello, G. Role of the electromagnetic field in the formation of domains in the process of symmetry-breaking phase transitions. Phys. Rev. A 2006, 74, 022105. [CrossRef]

32. Czerlinski, G.; Ryba, R. Coherence domains in living systems. J. Vortex. Sci. Technol. 2015, 2, 2. [CrossRef]

33. Montagnier, L.; Aissa, J.; Del Giudice, E.; Lavallee, C.; Tedeschi, A.; Vitiello, G. DNA waves and water. J. Phys. Conf. Ser. 2011, 306, 012007. [CrossRef]

34. Madl, P.; Del Giudice, E.; Voeikov, V.L.; Tedeschi, A.; Kolarž, P.; Gaisberger, M.; Hartl, A. Evidence of coherent dynamics in water droplets of waterfalls. Water 2013, 5, 57-68.

35. Carlon, H.R. Do clusters contribute to the infrared absorption spectrum of water vapor? Infrared Phys. 1979, $19,549-557$. [CrossRef]

36. Carlon, H.R. Variations in emission spectra from warm water fogs: Evidence for clusters in the vapor phase. Infrared Phys. 1979, 19, 49-64. [CrossRef]

37. Ryzhkina, I.S.; Murtazina, L.I.; Kiseleva, Y.V.; Konovalov, A.I. Supramolecular systems based on amphiphilic derivatives of biologically active phenols: Self-assembly and reactivity over a broad concentration range. Doklady Phys. Chem. 2009, 428, 201-205. [CrossRef]

38. Konovalov, A.I.; Ryzhkina, I.S. Formation of nanoassociates as a key to understanding of physicochemical and biological properties of highly dilute aqueous solutions. Russ. Chem. Bull. 2014, 63, 1-14. [CrossRef]

39. Yinnon, T.A.; Liu, Z.Q. Domains formation mediated by electromagnetic fields in very dilute aqueous solutions: 3 . Quantum electrodynamic analyses of experimental data on solutions of weak electrolytes and non-electrolytes. Water 2015, 7, 48-69.

40. Messori, C.; Prinzera, S.V.; di Bardone, F.B. Deep into the water: Exploring the hydro-electromagnetic and quantumelectrodynamic properties of interfacial water in living systems. Open Access Lib. J. 2019, 6, 92815. [CrossRef]

41. Ivanov, V.E.; Usacheva, A.M.; Chernikov, A.V.; Bruskov, V.I.; Gudkov, S.V. Formation of long-lived reactive species of blood serum proteins induced by low-intensity irradiation of helium-neon laser and their involvement in the generation of reactive oxygen species. J. Photochem. Photobiol. B Biol. 2017, 176, 36-43. [CrossRef]

42. Ivanov, V.E.; Karp, O.E.; Bruskov, V.I.; Andreev, S.N.; Bunkin, N.F.; Gudkov, S.V. Formation of long-lived reactive products in blood serum under heat treatment and low-intensity laser irradiation, their role in hydrogen peroxide generation and DNA damage. Indian J. Biochem. Biophys. 2019, 56, 214-223. 
43. Bunkin, N.F.; Lyakhov, G.A.; Shkirin, A.V.; Ignatiev, P.S.; Kobelev, A.V.; Penkov, N.V.; Fesenko, E.E. Mesodroplet heterogeneity of low-concentration aqueous solutions of polar organic compounds. Phys. Wave Phenom. 2019, 27, 91-101. [CrossRef]

44. Hwang, S.G.; Lee, H.S.; Lee, B.C.; Bahng, G. Effect of antioxidant water on the bioactivities of cells. Int J. Cell Biol. 2017, $2017,1917239$. [CrossRef]

45. Locke, B.R.; Shih, K.Y. Review of the methods to form hydrogen peroxide in electrical discharge plasma with liquid water. Plasma Sources Sci. Technol. 2011, 20, 034006. [CrossRef] 